\title{
Adenosine Deaminase Assay in Different Body Fluids for the Diagnosis of Tubercular Infection
}

\author{
Khandaker Shadia ${ }^{1, ~ *, ~ S . ~ M . ~ M o s t o f a ~ K a m a l ~}{ }^{2}$, Ahmed Abu Saleh ${ }^{1}$, Mohammed Nayem Hossain ${ }^{3}$, \\ Ratan Das Gupta ${ }^{4}$, Md. Ruhul Amin Miah ${ }^{1}$ \\ ${ }^{1}$ Department of Microbiology and Immunology, Bangabandhu Sheikh Mujib Medical University, Dhaka, Bangladesh \\ ${ }^{2}$ National Tuberculosis Reference Laboratory, Institute of Diseases of the Chest and Hospital (NIDCH), Dhaka, Bangladesh \\ ${ }^{3}$ Department of Surgery, Dhaka Medical College Hospital, Dhaka, Bangladesh \\ ${ }^{4}$ Department of Medicine, Dhaka Medical College Hospital, Dhaka, Bangladesh
}

\section{Email address:}

drsadialima@ymail.com (K. Shadia),ntrlnidchbd@yahoo.com (S. M. M. Kamal), aasaleh@gmail.com (A. A. Saleh), drhemuxl@yahoo.com (M. N. Hossain), dasgupta_ratan@yahoo.com (R. D. Gupta), ruhulamin53@gmail.com (M. R. A. Miah)

\section{To cite this article:}

Khandaker Shadia, S. M. Mostofa Kamal, Ahmed Abu Saleh, Mohammed Nayem Hossain, Ratan Das Gupta, Md. Ruhul Amin Miah. Adenosine Deaminase Assay in Different Body Fluids for the Diagnosis of Tubercular Infection. American Journal of Biomedical and Life Sciences. Vol. 3, No. 3, 2015, pp. 49-54. doi: 10.11648/j.ajbls.20150303.14

\begin{abstract}
Diagnosis of tuberculosis from different body fluids remains challenging due to various limitations of the conventional and molecular methods. We studied the role of adenosine deaminase (ADA) assay to diagnose tubercular infection in cerebrospinal fluid, peritoneal fluid and pleural fluid. Fifty three patients with tubercular meningitis, peritonitis and pleuritis were enrolled in this study on the basis of clinical, radiological, cytological, biochemical and somewhere bacteriological evidences. Cases positive by AFB smear, culture or PCR were considered as confirmed TB and other as probable TB cases. Another 28 non-TB cases were included as control. In 53 suspected TB cases ADA was found positive in highest 42 (79.2\%) cases, whereas smear and/ culture in $10(18.7 \%)$ and PCR in $18(33.9 \%)$ cases. ADA assay revealed $100 \%$ positivity in confirmed TB cases and $14.3 \%$ in non TB cases. The sensitivity and specificity of ADA was found $79 \%$ and $86 \%$ respectively when the cut off value was used $\geq 10 \mathrm{IU} / \mathrm{L}$ for CSF and $\geq 40 \mathrm{IU} / \mathrm{L}$ for pleural or peritoneal fluid. Mean ADA values of confirmed and probable TB cases were found significantly higher than that of non TB cases $(<0.05)$. Significance of difference was determined by ANOVA and Kruskal-Wallis test. Thus, adenosine deaminase assay in body fluids has proved to be efficient, reliable and simple method to diagnose tubercular meningitis, peritonitis and pleuritis.
\end{abstract}

Keywords: Body Fluid, Tuberculosis, Adenosine Deaminase Assay

\section{Introduction}

Tuberculosis (TB) is a protean disease caused by Mycobacterium tuberculosis (M. tuberculosis). Usually TB patients present with pulmonary manifestations. But extrapulmonary tuberculosis (EPTB) is not uncommon in TB endemic countries like Bangladesh. EPTB comprises 10-15\% of all TB cases in developing countries [1,2]. Pleural tuberculosis is one of the commonest forms of EPTB which is frequently presented with pleural effusion $[3,4]$. Likewise, about $78 \%$ tubercular peritonitis cases are presented with peritoneal effusion or ascites [5]. Another form of EPTB is tubercular meningitis which has most dangerous sequel if not treated promptly. Pleural and peritoneal tuberculosis is also to be treated as early as possible to minimize morbidity and mortality.

Diagnosis of TB from body fluids like pleural, peritoneal and cerebrospinal fluid (CSF) is challenging as all these fluid samples possess very few bacilli. Conventional methods like microscopy and culture are widely used for diagnosis, but sensitivity of AFB (Acid fast bacilli) smear is only 5-20\% and culture takes about three to six weeks time which may prolong the initiation of treatment. [6-9]. Histological evaluation following laparoscopy and/or biopsy in case of pleural and peritoneal TB brings about better sensitivity, also in smear and culture of the biopsy material $[8,10]$. But these methods are invasive, require greater expertise and may have sampling error and associated risk of complications $[9,10]$. Owing to this fact, many newer tests like antigen-antibody detection, antibody in lymphocyte supernatant (ALS) assay, cellular 
IFN- $\gamma$ release assays (IGRAs) and T-Spot have been developed [11]. But reliability of these tests in diagnosing active TB disease is not proven yet. With the advent of molecular technology polymerase chain reaction (PCR) has been developed for rapid detection of M. tuberculosis. PCR can reliably detect very low concentration of organism in extrapulmonary samples $[5,12]$. But requirement of dedicated laboratory areas, rigorous quality control and high cost of the test limits its routine use in resource poor countries. In this regard, adenosine deaminase (ADA) assay has shown to be a useful biochemical test in diagnosing TB from different body fluids, particularly in areas where the disease is prevalent [13-19].

ADA is an enzyme that catalyzes the deamination reaction which converts adenosine to inosine during proliferation and differentiation of lymphocytes. It also plays critical role in maturation of monocytes, thereby converts them into macrophage. So, ADA is being used as a biomarker of $\mathrm{T}$ cell activation and the conditions where macrophages are being infected. The level of ADA increases in biological fluids during tubercular infection due to stimulation of $\mathrm{T}$ cells by mycobacterial antigens [13].

As a TB-endemic country, a substantial number of EPTB cases are being reported each year with tubercular meningitis, peritonitis and pleuritis in Bangladesh. Major hindrance in the management of these EPTB cases is lack of a rapid, accurate and most importantly convenient diagnostic tool. Notably, under National Tuberculosis Program (NTP) AFB microscopy remains the single available laboratory test to detect TB cases in vast area of Bangladesh. So, the present situation does not permit to adopt newer molecular tests and even AFB culture as a routine method for $\mathrm{TB}$ diagnosis. ADA assay has been reported as rapid and cost effective method which can be adopted in even primary healthcare settings in developing countries. Moreover, many studies have confirmed the high sensitivity and specificity of this assay for early diagnosis of extrapulmonary TB, such as tuberculous pleuritis, pericarditis and meningitis [13-19]. To our knowledge no study has been done in Bangladesh by comparing its efficacy with that of conventional methods as well as molecular techniques. In the present study we aimed to evaluate the utility of adenosine deaminase (ADA) assay in detecting M. tuberculosis infections in CSF, pleural fluid and peritoneal fluid in comparison to conventional bacteriological methods and PCR.

\section{Materials and Methods}

This cross sectional study was conducted in the Department of Microbiology and Immunology, Bangabandhu Sheikh Mujib Medical University (BSMMU), Dhaka, Bangladesh in the year 2011. Clinical samples were collected from Dhaka Medical College Hospital and National Institute of Diseases of the Chest and Hospital (NIDCH), Dhaka.

\subsection{Selection of Cases}

Total 53 suspected TB cases either tuberculous pleuritis, peritonitis or meningitis was included in the study that fulfilled the following criteria. Notably, samples were collected before starting the anti-TB drugs.

a) Strong clinical suspicion of TB based on history and radiological evidences.

b) Cerebrospinal fluids having raised protein levels $(\geq 0.45$ $\mathrm{g} / \mathrm{L})$ and/or decreased glucose $(\leq 2.5 \mathrm{mmol} / \mathrm{L}$ or less than $2 / 3$ of blood sugar) and/or lymphocytic pleocytosis ( $\geq 50 \%$ lymphocytes).

c) Pleural and peritoneal fluids having raised protein levels (3 $\mathrm{g} / \mathrm{dl})$ and/or lymphocytic pleocytosis $(\geq 50 \%$ lymphocytes)

d) Revealed no growth in routine bacteriological culture media.

Another 28 cases of different clinical entity other than TB were taken as non TB control. CSF was collected from patients diagnosed as pyogenic meningitis (6), benign intracranial hypertension (2) and hydrocephalus (2), Pleural fluid from pleural empyema (5), nephrotic syndrome (2) and pleural malignancy (3); peritoneal fluid from chronic liver disease (5) and nephrotic syndrome (3). Diagnosis of the control cases were confirmed clinically and by appropriate laboratory tests.

\subsection{Categorization of Cases}

All the CSFs, pleural fluids and peritoneal fluids were undergone AFB microscopy, culture in Lowenstein-Jensen medium and PCR using IS6110 primer. On the basis of bacteriological evaluation suspected TB cases were then grouped into two categories.

1. Confirmed TB cases: Positive for M. tuberculosis either in AFB smear, culture or PCR.

2. Probable TB cases: Fulfilled the above mentioned inclusion criteria but negative in bacteriological tests.

\subsection{Laboratory Procedures}

\subsubsection{Sample Processing}

About 2-3 ml CSF, 20-30 ml Pleural fluid and 100-200 ml peritoneal fluid were collected from each patient by trained physician under aseptic condition. One $\mathrm{ml}$ of each specimen was subjected to biochemical, cytological and routine bacteriological tests. Remaining specimens were then centrifuged for 15 minutes (CSF at $10000 \mathrm{rpm}$ and pleural/peritoneal fluid at $3000 \mathrm{rpm}$ ) and deposits were used for staining, culture and PCR assay. Supernatant was preserved at $-20^{\circ} \mathrm{C}$ for $\mathrm{ADA}$ assay.

\subsubsection{AFB Smear and Culture}

For detection of $M$. tuberculosis Ziehl-Neelsen staining and then culture in Lowenstein-Jensen medium was performed.

\subsubsection{ADA Assay}

Adenosine deaminase level was determined from the supernatants of the centrifuged specimens. A commercial adenosine deaminase assay kit (Diazyme laboratories, USA) was used which follows the principle of modified Giusti method $[13,14,20]$. Cut-off value for tuberculosis was 
considered as $\geq 10 \mathrm{IU} / \mathrm{L}$ in $\mathrm{CSF}$ and $\geq 40 \mathrm{IU} / \mathrm{L}$ in pleural or peritoneal fluid $[6,7,13]$.

\subsubsection{Detection of M. Tuberculosis DNA}

\section{(i). Extraction of DNA}

The pellet was re-suspended in $135 \mu$ of lysis buffer [Prepared by mixing $20 \mu \mathrm{M}$ Tris $/ \mathrm{HCl}$ (pH 8.3), $1 \mathrm{mg} / \mathrm{ml}$ proteinase $\mathrm{K}, 0.5 \%$ Tween 20 and $10 \mathrm{ml}$ sterile distilled water] and then incubated at $56^{\circ} \mathrm{C}$ for 3 hours. At the end of incubation lysate was centrifuged at $12000 \mathrm{rpm}$ for $15 \mathrm{~min}$ and resultant pellet was resuspended with $100 \mu$ distilled water. This suspension was boiled at $95^{\circ} \mathrm{C}$ for 30 minutes in a water bath and then sonicated in an ultrasonication bath for $15 \mathrm{~min}$. Then centrifuged at $10,000 \mathrm{rpm}$ for 5 minutes; supernatant was recovered and stored at $4^{\circ} \mathrm{C}[21]$.

\section{(ii). Amplification of DNA by PCR}

PCR was performed to amplify $123 \mathrm{bp}$ of template targeting IS6110 element. Following primers were used-

IS-F 5'-CCT GCG AGC GTA GGC GTC GG- 3' and

IS-R 5'- CTC GTC CAG CGC CGC TTC GG-3'

The $25 \mu$ reaction mixtures contained $5 \mathrm{X}$ PCR buffer; $1.5 \mathrm{mM}$ of $\mathrm{MgCl} 2 ; 10 \mathrm{mM}$ dNTPs $0.2 \mathrm{mM}$ of primers, 1 units of Taq DNA Polymerase and $5 \mu 1$ of the DNA. Conditions followed were initial denaturation at $94^{\circ} \mathrm{C}$ for 5 minutes, followed by 31 cycles at $94^{\circ} \mathrm{C}$ for $45 \mathrm{sec}, 68^{\circ} \mathrm{C}$ for $45 \mathrm{sec}$ and $72^{\circ} \mathrm{C}$ for 2 minutes and final extension at $72^{\circ} \mathrm{C}$ for 10 minutes.

To eliminate false positive or false negative results each run of the PCR assay included one positive control (DNA of H37RV strain) and one negative control (PCR grade water).

\section{(iii). Detection of Amplified DNA by Gel Electrophoresis}

The amplified products were subjected to electrophoresis on a $1.5 \%$ agarose gel containing $0.5 \mu \mathrm{g} / \mathrm{ml}$ ethidium bromide and after illumination of the gel under U-V light results were documented in gel documentation system (BIORAD, Italy).

\subsection{Statistical Analysis}

All the data were analyzed using Statistical Package for Social Science (SPSS) 11.5 software for windows. To test the significance of difference between different groups ANOVA was used for normally distributed variables, whereas the Kruskal-Wallis test was used for variables having non-normal distribution. $\mathrm{P}$ value $<0.05$ was taken as minimum level of significance. As the rate of positivity by AFB smear and culture is very low sensitivity and specificity of ADA assay was calculated considering $53 \mathrm{~TB}$ cases as disease positive and 28 control cases as disease negative.

\subsection{Ethical Consideration}

Ethical clearance from the Institutional Ethical Review Committee was taken and informed written consent was sought from the patients before commencing the study.

\section{Results}

\subsection{Results of AFB Smear, Culture, PCR and ADA Assay in the Study Population}

Out of 53 suspected TB samples highest $42(79.2 \%)$ was positive by ADA. Only $10(18.7 \%)$ samples were positive by AFB smear and culture. IS6110 PCR was found positive in 18 $(33.9 \%)$ cases (Table 1). AFB smear, culture and PCR all together improved the sensitivity to $19(35.8 \%)$. These 19 cases were considered as confirmed TB cases, while rest of the suspected cases was regarded as probable TB cases. All the 28 samples from non TB control were found negative by AFB smear, culture or PCR.

Table 1. AFB smear, culture, PCR and ADA positivity in suspected TB and non TB cases.

\begin{tabular}{|c|c|c|c|c|c|}
\hline \multirow[b]{2}{*}{ Specimen } & \multirow[b]{2}{*}{ No of cases } & \multicolumn{4}{|c|}{ Positive by } \\
\hline & & $\begin{array}{c}\text { Smear or culture } \\
\text { n (\%) }\end{array}$ & $\begin{array}{l}\text { PCR } \\
\text { n (\%) }\end{array}$ & $\begin{array}{c}\text { Smear, culture or PCR } \\
\text { n (\%) }\end{array}$ & $\begin{array}{l}\text { ADA } \\
\text { n (\%) }\end{array}$ \\
\hline CSF & 27 & $\begin{array}{c}5 \\
(18.5)\end{array}$ & $\begin{array}{c}9 \\
(33.3)\end{array}$ & $\begin{array}{c}9 \\
33.3)\end{array}$ & $\begin{array}{c}23 \\
(85.1)\end{array}$ \\
\hline Peritoneal fluid & 10 & $\begin{array}{c}2 \\
(20.0)\end{array}$ & $\begin{array}{c}2 \\
(20.0)\end{array}$ & $\begin{array}{c}2 \\
(20.0)\end{array}$ & $\begin{array}{c}7 \\
(70.0)\end{array}$ \\
\hline Pleural fluid & 16 & $\begin{array}{c}3 \\
(18.8)\end{array}$ & $\begin{array}{c}7 \\
(43.7)\end{array}$ & $\begin{array}{c}8 \\
(50.0)\end{array}$ & $\begin{array}{c}12 \\
(75.0)\end{array}$ \\
\hline Total & 53 & $\begin{array}{c}10 \\
(18.7)\end{array}$ & $\begin{array}{c}18 \\
(33.9)\end{array}$ & $\begin{array}{c}19 \\
35.8)\end{array}$ & $\begin{array}{c}42 \\
(79.2)\end{array}$ \\
\hline
\end{tabular}

NB: All the non-TB samples were subjected to AFB smear, culture and PCR where none of the specimen was found positive.

\subsection{Comparative ADA Positivity among Confirmed, Probable and Non TB Cases}

While considering ADA positivity in confirmed and probable TB cases (Table 2), there was $100 \%$ positivity in all types of samples. About $67.6 \%$ probable cases were found positive for ADA, where pleural fluid showed the highest recovery rate of $70 \%$. ADA was higher than the cut-off value in 2 CSFs and 2 pleural fluids, together comprises $14.3 \%$ of the non TB cases. As the control cases were selected on the basis of detailed diagnostic evidences, these $14.3 \%$ cases indicated false positivity by ADA. 
Table 2. Comparison of ADA positivity among confirmed, probable and non TB cases.

\begin{tabular}{|c|c|c|c|c|}
\hline \multirow{2}{*}{ Cases } & \multicolumn{4}{|c|}{ ADA positivity in } \\
\hline & CSF & Peritoneal fluid & Pleural fluid & Total \\
\hline Confirmed TB cases & $\begin{array}{c}9(100 \%) \\
(n=9)\end{array}$ & $\begin{array}{c}2(100 \%) \\
(\mathrm{n}=2)\end{array}$ & $\begin{array}{c}8(100 \%) \\
(\mathrm{n}=8)\end{array}$ & $\begin{array}{c}19(100 \%) \\
(n=19)\end{array}$ \\
\hline Probable TB cases & $\begin{array}{c}12(66.7 \%) \\
(\mathrm{n}=18)\end{array}$ & $\begin{array}{c}5(62.5 \%) \\
(\mathrm{n}=8)\end{array}$ & $\begin{array}{c}6(75 \%) \\
(\mathrm{n}=8)\end{array}$ & $\begin{array}{c}23(67.6 \%) \\
(\mathrm{n}=34)\end{array}$ \\
\hline Non TB cases & $\begin{array}{c}2(20 \%) \\
(\mathrm{n}=10) \\
\end{array}$ & $\begin{array}{c}0(0 \%) \\
(\mathrm{n}=8)\end{array}$ & $\begin{array}{c}2(20 \%) \\
(\mathrm{n}=10)\end{array}$ & $\begin{array}{c}4(14.3 \%) \\
(\mathrm{n}=28) \\
\end{array}$ \\
\hline
\end{tabular}

\subsection{Mean ADA Value of CSF, Peritoneal Fluid and Pleural Fluid in the Study Population}

Mean ADA value in confirmed TB cases were $17.9 \pm 2.7$, $96.3 \pm 24.1$ and $71.9 \pm 32.7$ respectively in CSF, peritoneal fluid and pleural fluid. These values were significantly higher than $5.3 \pm 4.1,11.1 \pm 9.6,20.6 \pm 16.9$ values of non TB cases. The values for the same samples in probable TB cases were
$16.8 \pm 5.5,54.5 \pm 28.6$ and $52.5 \pm 31.0$ which were also significantly higher than those of the non TB cases (Table 3 ). In each of the comparison $p$ value was found $\leq 0.05$.

The sensitivity and specificity of ADA was found $79 \%$ and $86 \%$ respectively when the cut off value used $\geq 10 \mathrm{IU} / \mathrm{L}$ in $\mathrm{CSF}$ and $\geq 40 \mathrm{IU} / \mathrm{L}$ in pleural or peritoneal fluid.

Table 3. Mean ADA values of CSF, peritoneal fluid and pleural fluid in confirmed, probable and non TB cases.

\begin{tabular}{|c|c|c|c|}
\hline \multirow{2}{*}{ Samples } & \multicolumn{3}{|c|}{ ADA value in IU/L (Mean \pm SD) } \\
\hline & CSF & Peritoneal fluid & Pleural fluid \\
\hline Confirmed TB group & $17.9 \pm 2.7$ & $96.3 \pm 24.1$ & $71.9 \pm 32.7$ \\
\hline Probable TB group & $16.8 \pm 5.5$ & $54.5 \pm 28.6$ & $52.5 \pm 31.0$ \\
\hline Non TB group & $5.3 \pm 4.1$ & $11.1 \pm 9.6$ & $20.6 \pm 16.9$ \\
\hline
\end{tabular}

\section{Discussion}

As Bangladesh is TB-endemic country a considerable number of TB patients are presented with tuberculous pleuritis, peritonitis or meningitis. Due to lack of appropriate laboratory methods, the diagnosis of these cases largely depends on clinical suspicion and non-microbiological parameters. Consequently, the cases having atypical clinical presentation remain undiagnosed and even untreated. In this cross sectional study, out of 53 suspected TB samples only $18.7 \%$ revealed smear and culture positivity. The poor sensitivity of AFB smear and culture has widely been reported in many other studies [6-9].

The present study demonstrated $33.9 \%$ PCR positivity among suspected TB cases which was higher than that of the bacteriological methods. But this rate of PCR positivity is inferior comparable to different other studies done with body fluids $[7,12,22]$. PCR positivity largely depends on sample volume, processing, stringent operation and expertise. As a result several authors reported varying degree of sensitivity of this test. Another inconvenience of PCR in body fluids is presence of inhibitors, which negatively influence the result. This problem can be overcome by a multistep process of removing PCR inhibitors and thus improve the recovery of purified M. tuberculosis DNA [22]. Most importantly in this study PCR was performed targeting IS6110 gene sequence which is recently been reported to be absent in genome of some isolates of M. tuberculosis in south-east India, Tanzania, Malaysia, Oman and Denmark [23,24]. So, IS6110 PCR result sometimes found negative in TB cases. Use of combination of primers targeting different site of mycobacterial genome or using nested PCR may improve the detection of $M$. tuberculosis.
In 53 suspected $\mathrm{TB}$ cases adenosine deaminase assay demonstrated highest positivity among all the methods applied in this study. In about $85 \%$ CSF ADA value exceeded the diagnostic cut-off for tuberculosis. For peritoneal and pleural fluid raised ADA value was found in $70 \%$ and $75 \%$ cases, respectively. In a considerable number of suspected TB cases (11 out of 53) ADA activity was found negative. In this study, besides bacteriological confirmation, cases enrolled on the basis of clinical, radiological or cytological $(\geq 50 \%$ lymphocytes) evidences. So, there may be some overlapping features with other clinical conditions that influenced the results. Nevertheless, in this study bacteriologically confirmed all the 19 cases $(100 \%)$ showed a distinct higher value of ADA which signifies the precision of this test. Moreover, among bacteriologically negative 34 probable TB cases $67.6 \%$ cases was found positive with highest detection rate in pleural fluid (75\%). This finding is in concordance with the study of Kashyap et al. who found $96 \%$ sensitivity in culture positive CSF and 78\% in culture negatives [16]. Ocana et al. and Martinez- Vazquez et al found $100 \%$ positivity of ADA assay in culture positive pleural and peritoneal fluids respectively $[17,18]$. In addition, the mean ADA value of confirmed TB and probable $\mathrm{TB}$ cases was found significantly higher than that of non TB cases $(\mathrm{P}<0.05)$ which indicates the strong relationship between presences of $\mathrm{TB}$ infection and $\mathrm{ADA}$ activity.

As discussed earlier, the sensitivity of AFB smear and culture is very low in diagnosing extrapulmonary TB. Thus it is not reliable to judge any other tests considering these methods as gold standard. Therefore, in the present study a suspected TB case was regarded as disease positive and against this variable sensitivity of ADA was found $79.2 \%$. Out of 28 cases in the non TB control group two CSFs and two 
pleural fluids revealed ADA positivity, consequently specificity of the test found $85.7 \%$. Of note, in few other conditions other than TB like pyogenic meningitis and empyema where fluids contain high cell counts can depict high total ADA value. It makes dilemma in differentiating non tubercular conditions from tuberculous origin. ADA value detected in most of the assays is the total ADA which includes both ADA-1 and ADA-2 isoenzymes. In tubercular disease particularly elevated isoform is ADA2 which gives rise to the elevation of total ADA also $[9,13]$. So, analysis of specific ADA2 isoenzyme may help to correctly classify these cases. Furthermore, the sensitivity and specificity of ADA largely depends upon the setting of cut-off values $[7,13,16,19]$. Thus specificity can be improved by elevating the cut-off value and overlapping values between suspected TB and non TB cases can be avoided.

\section{Conclusion}

In conclusion, adenosine deaminase level in body fluids is a good indicator of extrapulmonary TB especially where clinical suspicion is high. It can be performed with minimum time, cost and equipments compared to PCR. However, culture is still the gold standard and superior to ADA in determining drug resistance prior initiation of treatment. So, for achieving best clinical outcome ADA values should be carefully correlated with the clinical and other biochemical parameters and cases should be confirmed bacteriologically where facility is available. Meanwhile empirical treatment can be employed in patients having high ADA value as it efficiently differentiates TB from non-TB cases.

\section{Acknowledgements}

Authors are thankful to Dr. ASM Alamgir and Dr. Sayera Banu for providing tremendous support in arranging PCR primers, reagents and also for giving opportunity to share their laboratory facilities.

\section{References}

[1] WHO 2012 Report: TB in South East Asia - country profile: Bangladesh. World Health Organization, Geneva 2012.

[2] J.B. Mehta, A. Dutt, L. Harvill and K.M. Mathews, "Epidemiology of extrapulmonary tuberculosis: a comparative analysis with pre-AIDS era," Chest, vol. 99, pp. 1134-1138, 1991.

[3] A.A. Lazarus, S. McKay, R. Gilbert, "Pleural tuberculosis," Dis Mon, vol. 53, pp. 16-21, 2007.

[4] P.C. Wong, "Management of tuberculous pleuritis: can we do better?," Respirology, vol. 10, pp. 144-8, 2005.

[5] F.M. Sanai, K.I.Bzeizi, "Systematic review: tuberculous peritonitis--presenting features, diagnostic strategies and treatment," Aliment Pharmacol Ther, vol. 22, pp. 685-700, 2005.
[6] S. Ahmed, R. Fatema, A.A. Saleh, H. Sattar and M.R.A. Miah, "Diagnostic significance of pleural fluid adenosine Deaminase activity in tuberculous pleurisy," Ibrahim Med. Coll J, vol. 5(1), pp. 1-5, 2011.

[7] S.K. Sharma, A. Mohan, "Extrapulmonary tuberculosis Review article," Indian J Med Res, vol. 120, pp. 316-53, 2004.

[8] C.E. Bueno, M.G. Clemente, B.C. Castro, L.M. Martín, S.R. Ramos, A.G. Panizo, J.M. Glez-Río, "Cytologic and bacteriologic analyzes of fluid and pleural biopsy with cop's needle," Arch Intern Med, vol. 150 (6), pp. 1190-1194, 1990.

[9] P. Mrinal, D. Subinay, “Adenosine deaminase and its isoenzyme as a diagnostic marker in tubercular pleural effusion,” J Drug Del Ther, vol. 4(1), pp. 18-21, 2014.

[10] S.K. Sharma, M. Tahir, A. Mohan, D. Smith-rohrberg, H.K. Mishra, R.M. Pandey, "Diagnostic accuracy of ascitic fluid INF- $\gamma$ and adenosine deaminase assays in the diagnosis of tuberculous ascites," J Interferon \& Cytokine Res, vol. 26, pp. 484-488, 2006

[11] P.D. Davies, B. Chakrabarti, P. Albert, "Latest development in the diagnosis of tuberculosis," European Infec Dis, pp. 75-76, 2008.

[12] M. Caws, S.M. Wilson, C. Clough, F. Drobniewski, "Role of IS6110-Targeted PCR, Culture, Biochemical, Clinical, and Immunological Criteria for Diagnosis of Tuberculous Meningitis," Clin Microbiol, vol. 38, pp. 3150-3155, 2000.

[13] L. Boonyagars, S. Kiertiburanakul, "Use of Adenosine Deaminase for the Diagnosis of Tuberculosis: A Review," J Infect Dis Antimicrob Agents, vol. 27(2), pp. 111-118, 2010.

[14] D. Song, A.R. Lun, W. Chiu, "Diazyme adenosine deaminase in the diagnosis of tuberculous pleural effusion: method evaluation and clinical experiences in a New Zealand population," NZ J Med Lab Science, vol. 64, pp. 11-13, 2010.

[15] M.C. Feres, M.C. Martino, S. Maldijian, F. Batista, J.A. Gabriel, S. Tufik, "Laboratorial validation of an automated assay for the determination of adenosine deaminase activity in pleural fluid and cerebrospinal fluid," J Bras Pneumol, vol. 34, pp. 1033-9, 2008.

[16] R.S. Kashyap, R.P. Kainthla, A.V. Mudaliar, H.J. Purohit, G.M. Taori and H.F. Daginawala, "Cerebrospinal fluid adenosine deaminase activity: A complimentary tool in the early diagnosis of tuberculous meningitis," Cereb Fluid Res, vol. 3, pp. 5, 2006.

[17] I. Ocana, J.M. Martinez-Vazquez, R.M. Segura, T. Fernandez-De-Sevilla and J.A. Capdevila, "Adenosine Deaminase in Pleural Fluids," Chest, vol. 84(1). pp. 51-53, 1983.

[18] J.M. Martinez-Vazquez, I. Ocana, E. Ribera, R.M. Segura and C. Pascual, "Adenosine deaminase activity in the diagnosis of tuberculous peritonitis," Gut, vol. 27, pp. 1049-1053, 1986.

[19] A. Riquelme, M. Calvo, F. Salech, S. Valderrama, A. Pattillo, M. Arellano, M. Arrese, A. Soza, P. Viviani and L.M. Letelier, "Value of Adenosine Deaminase (ADA) in Ascitic Fluid for the Diagnosis of Tuberculous Peritonitis," J Clin Gastroenterol, vol. 40, pp. 705-710, 2006.

[20] G. Ellis, D.M. Goldberg, "A reduced nicotinamide adenine dinucleotide--linked kinetic assay for adenosine deaminase activity," J Lab Clin Med, vol. 76, pp. 507-17, 1970. 
[21] K. Shadia, S. Anwar, S. Banu, A. A. Saleh and M. R. A. Miah, "Comparison of three mycobacterial DNA extraction methods from extrapulmonary samples for PCR assay," Ibrahim Med. Coll. J, vol 6(1), pp. 9-11, 2012.

[22] M. Hajia, M. Rahbar, R. Amini, "Is PCR assay reliable for diagnosis of extrapulmonary tuberculosis?," African J Microbiol Res, vol. 3(12), pp. 877-881, 2009.
[23] S. Das, C.N. Paramasivan, D.B. Lewis, R. Prabhakar, P.R. Narayanan, "IS6110 restriction fragment length polymorphism typing of clinical isolates of Mycobacterium tuberculosis from patients with pulmonary tuberculosis in Madras, south India," Tubercle Lung Dis, vol. 76, pp. 550-4, 1995.

[24] N.G. Fumokong, T.H. Tang S. Al-Maamary, "Insertion sequence typing of $M$. tuberculosis: Characterization of a widespread sub-type with single copy of IS6110," Tubercle Lung Dis, vol. 75, pp. 435-440, 1994. 